\title{
Does Consumer Awareness of Neonicotinoid Insecticides Influence Their Preferences for Plants?
}

\author{
Alicia Rihn and Hayk Khachatryan ${ }^{1}$ \\ Food and Resource Economics Department and Mid-Florida Research and \\ Education Center, University of Florida, 2725 S. Binion Road, Apopka, \\ FL 32703
}

Additional index words. demand, in-store promotions, neonic, pollinator insects, survey, purchasing behavior

\begin{abstract}
Consumer awareness of neonicotinoid (neonic) insecticides is growing (in part) due to increased publicity and media attention. Environmental groups want neonic insecticides to be banned because of their perceived potential negative consequences on nontarget species (especially bees and other pollinator insects). Several retail outlets and governmental agencies are now requiring the ornamental horticulture industry (hereafter, green industry) to label plants grown using neonic insecticides. Although the scientific value of the mandatory labeling policies are debatable, neonic labeling may negatively influence consumers' demand for plants. Research on consumers' awareness of neonic insecticides is limited, and the extent to which awareness influences preferences and shopping behavior is less understood. This manuscript addresses these research gaps by investigating correlations between awareness of neonic insecticides, knowledge about related topics (e.g., gardening and pollinator insect health), and purchase likelihood, using an online survey of 921 U.S. consumers. Results indicate that only $24 \%$ of surveyed plant purchasers are aware of neonic insecticides. Consumers who are aware of neonic insecticides are more knowledgeable about plants that improve pollinator health and entomology than those who are not aware. Labels with "neonic-free" wording were the least preferred and influential pollinator-related in-store promotion. However, awareness of neonic insecticides was positively correlated with consumers' purchase likelihood for "neonic-free" plants. Overall, awareness influences consumers' shopping behavior, which could necessitate altering green industry pest management strategies as consumers' awareness of neonic insecticides increases due to the negative publicity surrounding it.
\end{abstract}

Recently, research on pollinator insects has escalated due to reports on declining pollinator populations. Previous studies on pollinator insects and their services have focused on the impacts of insecticides (Fairbrother et al., 2014; Goulson, 2013; Pimentel, 2005; US-EPA, 2013), economic impacts of pollination (Gallai et al., 2009; Hanley et al., 2015; Pilling et al., 2013), environmental consequences and benefits (Frankie et al., 2005; McIntyre and Hostetler, 2001; Wratten et al., 2012), and natural resource conservation measures (Breeze et al., 2015; Diffendorfer et al., 2014; Mwebaze et al., 2010). One topic that has been at the forefront of discussions on pollinator insect declines is insecticide use. However, research findings on the effects of insecticide use on pollinator insects' health are inconclusive (Fairbrother et al., 2014; Goulson, 2013; Pilling et al., 2013). Nevertheless, insecticide usage has been linked to declines in honeybee and pollination services reaching \$284 million/year in the United States (Pimentel, 2005). This has global economic implications, given pollinator insects' estimated annual contribution of

Received for publication 30 Oct. 2015. Accepted for publication $9 \mathrm{Feb} .2016$.

1Corresponding author. E-mail: hayk@uff.edu.
$€ 153$ billion/year for food crops worldwide (Gallai et al., 2009).

Research has shown consumers value pollinator services and conservation efforts (Breeze et al., 2015; Diffendorfer et al., 2014; Mwebaze et al., 2010). For instance, UK consumers are willing to pay $£ 379$ million ( $£ 13.4$ per taxpayer) in taxes to aid pollinators (Breeze et al., 2015). Similarly, Mwebaze et al. (2010) found UK households are willing to pay $£ 1.37$ per week for bee protection policies, which equates to $£ 1.77$ billion per year. In the United States, consumers are willing to pay $\$ 4.78-6.64$ billion (in a total onetime payment) toward purchasing monarch-friendly plants and donating to conservation organizations (Diffendorfer et al., 2014). Although consumers want to aid pollinator insects through conservation measures, very few studies address consumer behavior toward pollinator insects or their interactions with neonic insecticides.

Neonic insecticides are of particular interest due to controversial research findings and negative publicity (US-EPA, 2013). Neonics provide systemic protection to plants from a variety of insect pests (Sánchez-Bayo et al., 2013). Systemic protection means the insecticide is present within plant tissues that are readily consumed by many insect pests, which has led to concerns about potential negative impacts on nontarget species (i.e., insect pollinators, pets, and humans) that come in contact with and/or consume portions of treated plants. However, Fairbrother et al. (2014) determined that neonics do not play a significant role in declining bee health when compared with parasites, diseases, habitat loss, queen failure, and poor nutrition. Furthermore, when applied according to the label, neonics appear to have minimal risks to pollinator insects (Pilling et al., 2013). Other studies argue that neonic insecticides impact bees health more subtly, by decreasing bee homing and foraging ability, colony growth, learning, disease resistance, and hive hygiene, which are detrimental to colony health (Goulson, 2013; van der Sluijs et al., 2013). However, Blacquiére et al. (2012) states neonics' lethal and sublethal effects on pollinators only occur in laboratory experiments, not in the field setting.

Despite the lack of consensus on neonic insecticides' impact on pollinator insects' health, environmental groups urge retail outlets and green industry stakeholders (i.e., plant growers and retailers) to supply consumers with plants grown without using neonics. This is concerning for the green industry because neonic insecticides are effective against a wide range of pests, have low mammalian toxicity, and are less expensive compared with many alternatives (Goulson, 2013; Sánchez-Bayo et al., 2013; Zalom et al., 2005). In addition, they help to minimize plant damage, which improves plant salability, margins, and profits (Sadof and Raupp, 1987; Sánchez-Bayo et al., 2013). In response, several retailers (including Home Depot) and governmental organizations (i.e., UK Parliament) now selectively purchase neonic-free plants and/or require mandatory labeling (US-EPA, 2013). Mandatory labeling can affect the marketplace, product availability, production costs, the competitive environment, and profits (Bonroy and Constantoatos, 2014). Furthermore, labeling and other promotional efforts can influence consumer behavior. For instance, Anella et al. (2001) determined the Oklahoma Proven Plant Campaign (promoted through labels/tags, posters, billboards, and pot stakes) increased plant sales by $81 \%$. In turn, this leads to the question of how does "neonic-free" labeling influence consumer behavior toward plants? Currently, there is insufficient quantitative evidence to provide a definitive answer to this question.

Although environmental groups are pushing for the regulation (and banning) of neonic pesticide use on plants, to date, very few studies actually assess consumer (i.e., end users) awareness of neonic insecticides and the influence of "neonic-free" labels on their purchasing behavior. Wollaeger et al. (2015) reported that nearly $57 \%$ of consumers do not understand the term "neonic-free" and 70\% indicated low knowledge of "neonic-free" production methods. This low awareness and 


\begin{tabular}{|c|c|c|c|c|}
\hline & & $\begin{array}{c}\text { Sample } \\
\text { Mean }\end{array}$ & $\frac{\text { Neonic aware group }}{\text { Mean }}$ & $\frac{\frac{\text { Neonic not aware group }}{\text { Mean }}}{}$ \\
\hline & Description & (SE) & (SE) & (SE) \\
\hline Percent & Percent of total sample & 100 & 24.1 & 75.9 \\
\hline Age & Age (in years) of participant & $51.30(34.41)$ & $41.26(14.55)^{\mathrm{z}}$ & $54.46(38.06)^{\mathrm{z}}$ \\
\hline Gender & $\begin{array}{l}1=\text { male } \\
0=\text { female }\end{array}$ & $0.42(0.49)$ & $0.48(0.50)^{z}$ & $0.40(0.49)^{z}$ \\
\hline Education & $\begin{array}{l}\text { Highest level of education completed } \\
1=\text { bachelor's degree or graduate school/degree } \\
0=\text { otherwise }\end{array}$ & $0.49(0.50)$ & $0.56(0.50)^{z}$ & $0.46(0.50)^{\mathrm{z}}$ \\
\hline Income & $\begin{array}{l}2014 \text { gross household income } \\
1=<\$ 20 \mathrm{k} \\
2=\$ 21 \mathrm{k}-30 \mathrm{k} \\
3=\$ 31 \mathrm{k}-40 \mathrm{k} \\
4=\$ 41 \mathrm{k}-50 \mathrm{k} \\
5=\$ 51 \mathrm{k}-60 \mathrm{k} \\
6=\$ 61 \mathrm{k}-70 \mathrm{k} \\
7=\$ 71 \mathrm{k}-80 \mathrm{k} \\
8=\$ 81 \mathrm{k}-90 \mathrm{k} \\
9=\$ 91 \mathrm{k}-100 \mathrm{k} \\
10=>\$ 100 \mathrm{k}\end{array}$ & $5.83(2.99)$ & $5.85(2.82)$ & $5.83(3.04)$ \\
\hline Household & Number of people in household & $2.76(1.36)$ & $3.14(1.52)^{\mathrm{z}}$ & $2.64(1.28)^{z}$ \\
\hline Relationship & $\begin{array}{l}1=\text { in relationship or married } \\
0=\text { otherwise }\end{array}$ & $0.74(0.44)$ & $0.70(0.46)$ & $0.75(0.44)$ \\
\hline Region-midwest & $\begin{array}{l}1=\text { midwest resident } \\
0=\text { otherwise }\end{array}$ & $0.24(0.43)$ & $0.25(0.43)$ & $0.24(0.43)$ \\
\hline Region-northeast & $\begin{array}{l}1=\text { northeast resident } \\
0=\text { otherwise }\end{array}$ & $0.23(0.42)$ & $0.26(0.44)$ & $0.23(0.42)$ \\
\hline Region-southeast & $\begin{array}{l}1=\text { southeast resident } \\
0=\text { otherwise }\end{array}$ & $0.27(0.44)$ & $0.22(0.41)$ & $0.28(0.45)$ \\
\hline Region-northwest & $\begin{array}{l}1=\text { northwest resident } \\
0=\text { otherwise }\end{array}$ & $0.06(0.24)$ & $0.06(0.24)$ & $0.06(0.24)$ \\
\hline Region-southwest & $\begin{array}{l}1=\text { southwest resident } \\
0=\text { otherwise }\end{array}$ & $0.16(0.37)$ & $0.19(0.39)$ & $0.16(0.36)$ \\
\hline Region - other & $\begin{array}{l}1=\text { other region resident } \\
0=\text { otherwise }\end{array}$ & $0.03(0.18)$ & $0.03(0.18)$ & $0.03(0.18)$ \\
\hline Purchased insecticides & $\begin{array}{l}1=\text { purchased and used insecticides within the past } 12 \mathrm{mo} . \\
0=\text { otherwise }\end{array}$ & $0.80(0.40)$ & $0.92(0.27)^{z}$ & $0.77(0.42)^{\mathrm{z}}$ \\
\hline
\end{tabular}

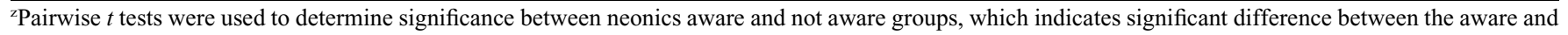
not aware groups at $P \leq 0.05$.

confusion about the effects of neonic insecticides has implications for the green industry as it has been shown to influence consumers' purchasing decisions (Chi et al., 2009; Krystallis and Chrysochou, 2011). Specifically, awareness increases consumers' purchase likelihood (Krystallis and Chrysochou, 2011) unless the consumer is already loyal to an existing brand or had preexisting perceptions of superior quality for another brand (Chi et al., 2009). Since awareness impacts consumer behavior for other products, how does consumer awareness of neonic insecticides influence their preferences for plants? Furthermore, are consumers even aware of neonic insecticides and how does that affect their behavior? Given low levels of awareness of neonics among the general public (Wollaeger et al., 2015), should the green industry produce and promote plants as "neonic-free" and educate consumers about neonic insecticides or not? At the center of these uncertainties is the question of what influence would "neonic-free" labeling have on consumer preferences and demand for plants?

To address these questions, we conducted an online survey of U.S. consumers. With the overall goal to identify how consumers' awareness of neonic insecticides affects their purchasing behavior, the following hypotheses were tested:

1. Consumers' knowledge of pollinatorrelated topics (i.e., gardening/landscaping, pollinator insect health, and entomology) is positively correlated with their awareness of neonic insecticides.

2. Consumers who are aware of neonic insecticides are more likely to purchase plants with "neonic-free" labels than those who are not aware of neonics.

\section{Materials and Methods}

An online survey was used to assess U.S. consumers' preferences for "neonicfree" plant labels. Survey questions were designed based on relevant literature, visiting retail outlets, and consulting industry professionals. Survey questions consisted of consumers' past purchasing behavior, awareness of neonic insecticides, general knowledge, attitude toward attracting pollinator insects, purchase intentions, pollinator promotion wording, and six standard sociodemographic questions (i.e., age, gender, income, education, household, and relationship status). The survey and experimental protocol were approved by the institution review board.
The survey was conducted in Jan. 2015 using a third-party contractor (Qualtrics Online Survey Software; Qualtrics, LLC, Provo, UT). An online survey was used to most efficiently reach a broad demographic of participants across the United States (McDaniel and Gates, 2010). Participants were compensated with online reward points through the third party contractor. A total of 2766 people started the survey, of which, 921 participants (33\% of all respondents) agreed to the consent form, passed the three validation questions (Validation questions were equally spaced throughout the survey and included 1) to ensure you are reading the statements, please select 4 as your answer to this statement; 2) this is an attention question, please select "disagree" as your answer to this statement; and 3) this is an attention question, please select "moderately characteristic" as your answer to this statement), and had purchased plants within the past 12 months [The screening question "Have you purchased plants in the past 12 months? (yes/ no)" was used to identify plant purchasers for the study]. Validation questions have been used to reduce bias and improve response validity (McDaniel and Gates, 2010). Only plant purchasers were included in the analysis since these individuals have the greatest impact on sales and demand. 


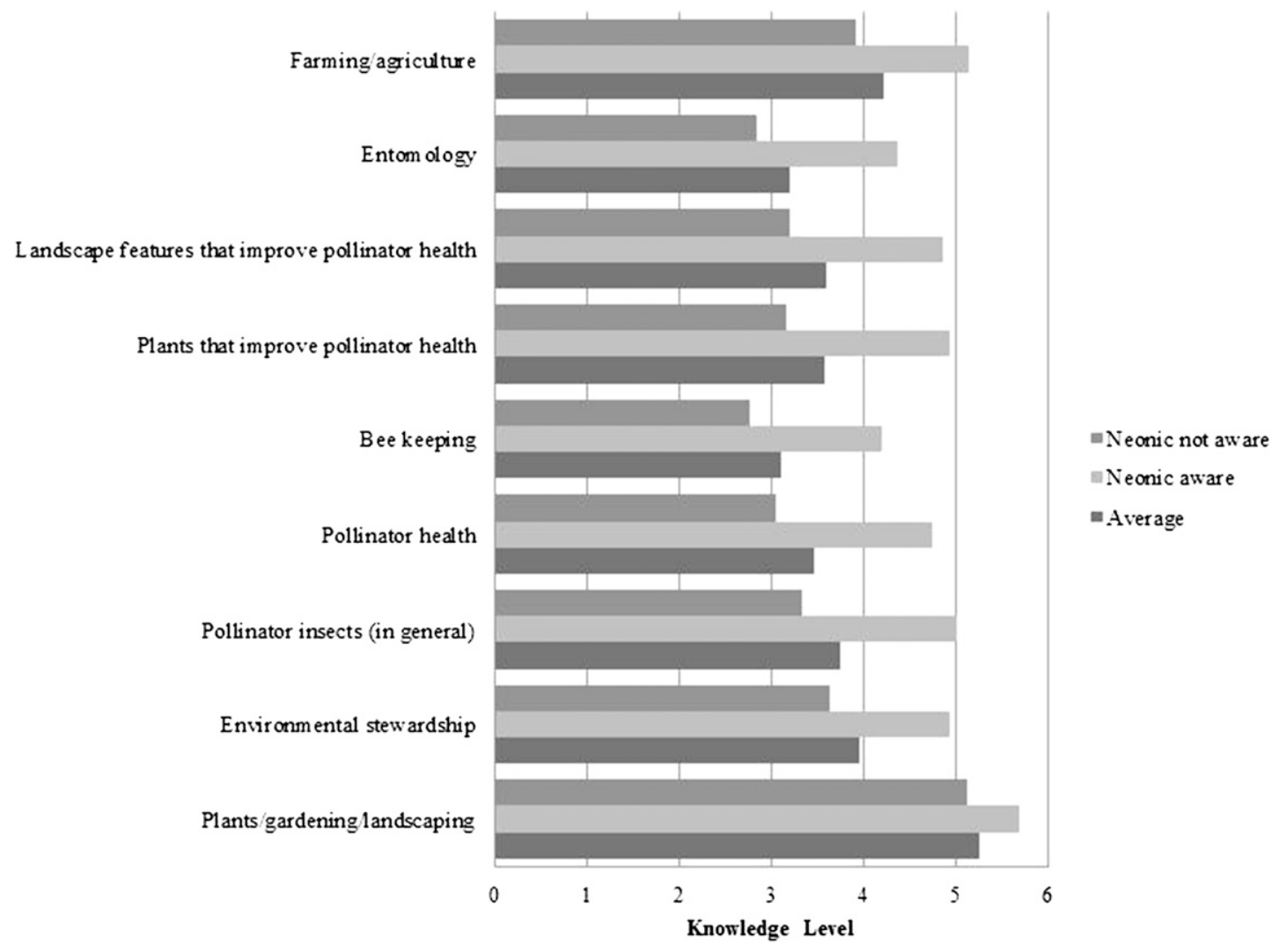

Fig. 1. Participants' level of knowledge about different factors related to pollinators $(1=$ not at all knowledgeable; $7=$ very knowledgeable). Pairwise $t$ test results indicate that all factors were significant between aware and not aware consumer groups with $P<0.001$.

Table 2. Binary logit regression model estimates indicating how consumers' knowledge impacts their awareness of neonicotinoid insecticides.

\begin{tabular}{|c|c|c|}
\hline Variables & Coefficient (SE) & \\
\hline \multicolumn{3}{|l|}{ Related topics } \\
\hline Plants/gardening/landscaping & $-0.01(0.30)$ & \\
\hline Environmental stewardship & $0.22(0.23)$ & \\
\hline Pollinator insects (in general) & $0.52(0.29)$ & \\
\hline Insect pollinator health & $0.04(0.28)$ & \\
\hline Bee keeping & $0.34(0.24)$ & \\
\hline Plants that improve pollinator health & $0.68(0.27)$ & * \\
\hline Landscape features that improve pollinator health & $0.34(0.29)$ & \\
\hline Entomology & $0.65(0.23)$ & ** \\
\hline Farming/agriculture & $0.20(0.23)$ & \\
\hline \multicolumn{3}{|l|}{ Demographic variables } \\
\hline Age & $-0.04(0.01)$ & $* * *$ \\
\hline Gender & $0.37(0.19)$ & \\
\hline Income & $-0.03(0.04)$ & \\
\hline Education & $0.47(0.21)$ & $*$ \\
\hline Household & $0.06(0.07)$ & \\
\hline Relationship & $-0.20(0.22)$ & \\
\hline Constant & $-0.55(0.47)$ & \\
\hline Log likelihood & -374.67 & \\
\hline Likelihood ratio $\chi^{2}(15)$ & 253.79 & \\
\hline Probability $>\chi^{2}$ & 0.000 & \\
\hline Pseudo $R^{2}$ & 0.25 & \\
\hline
\end{tabular}

***,**, *Significant at $P \leq 0.001,0.01$, and 0.05 , respectively.

Data were analyzed using Stata software (StataCorp LP, College Station, TX). To assess the impact of neonic insecticides awareness, consumers were divided into "aware" (24\% of the sample) and "not aware" (76\% of the sample) groups. Means were obtained for each group and pairwise $t$ tests were used to determine significance between the groups. To test hypothesis 1 (i.e., consumers' knowledge of pollinator-related topics improves their awareness of neonic insecticides), a binary logit regression model was used. Knowledge was assessed by asking participants how knowledgeable they were about the different topics $(1=$ not at all knowledgeable; 7 = very knowledgeable). Binary knowledge variables were generated where participants were considered knowledgeable if they selected $\geq 5$ since a value of 4 correlated to 'neither knowledgeable nor not knowledgeable' and less than 4 indicated low knowledge. The knowledge variables were the independent variables and neonics awareness $(1=$ aware; $0=$ not aware $)$ was the dependent variable. Finally, to test hypothesis 2 (i.e., neonic aware consumers are more likely to purchase plants with "neonicfree" labels), an ordered logit regression model was used. An ordered logit model was used because the dependent variable was ordinal. Specifically, the dependent variable was how the "neonic-free" label would influence the consumers' purchase likelihood $(1=$ very unlikely; $7=$ very likely). The independent variables included participants' awareness of neonics and sociodemographic variables.

\section{Results}

Sample demographic characteristics. A total of 921 consumers from across the United States participated in the study. Forty-two percent of participants were male and $49 \%$ of the sample had bachelor's degree or higher at the time of the study (Table 1). The average age of participants was 51 years. Most participants' households earned between \$51,000-60,000 in 2014. The average household size was two to three people. Seventy-four percent were married or in a relationship. Most respondents $(27 \%)$ were from the southeast region of the United States, followed by the midwest, northeast, southwest, northwest, and other regions (including Alaska and Hawaii). Eighty percent of participants had purchased and used insecticides within 


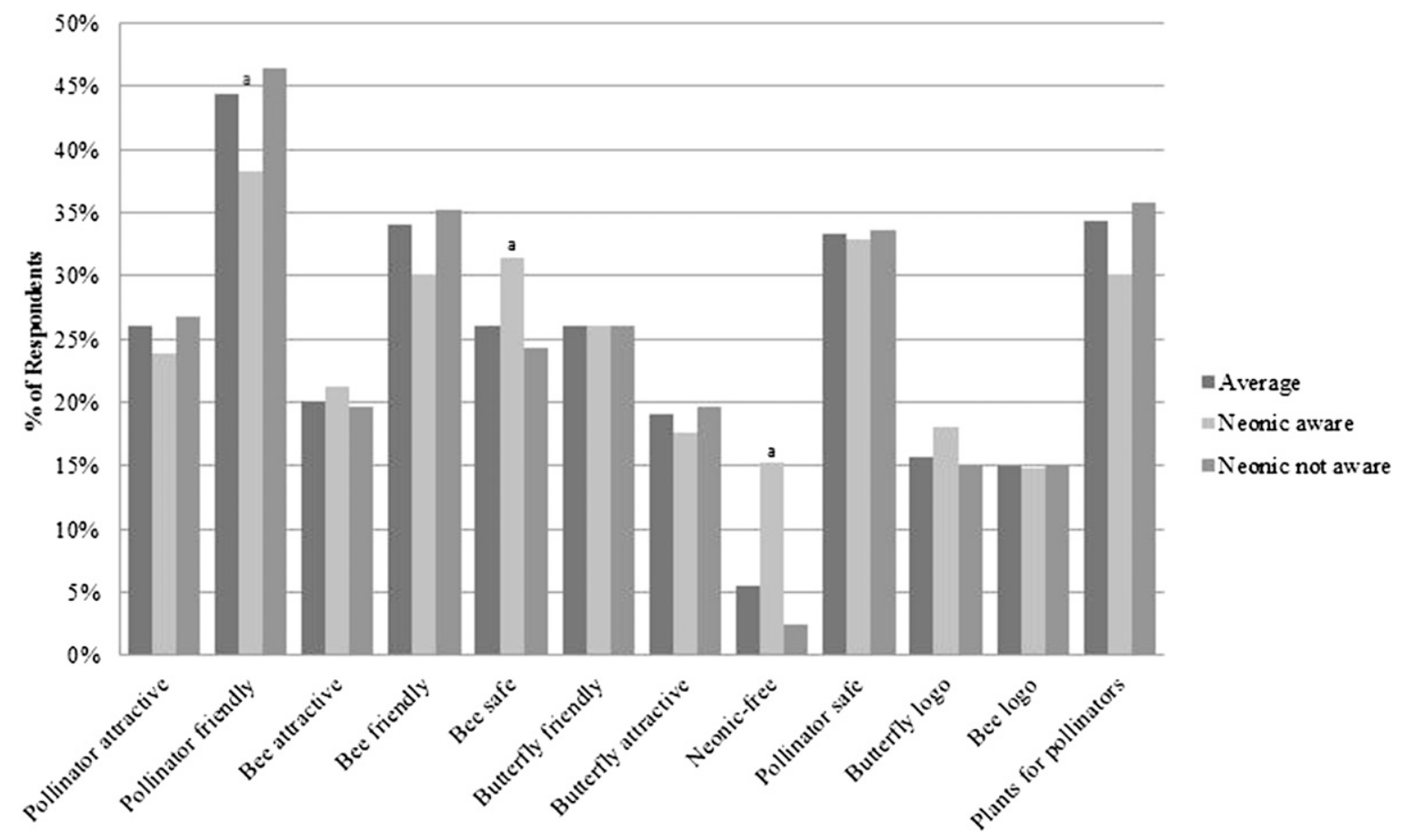

Fig. 2. Percent of consumers preferring different in-store pollinator-related promotions. Participants were asked to indicate their top three choices; hence, percentages do not sum to $100 \%$. ${ }^{\text {PPairwise } t} t$ test results indicate significance between neonic aware and not aware groups at $P<0.05$.

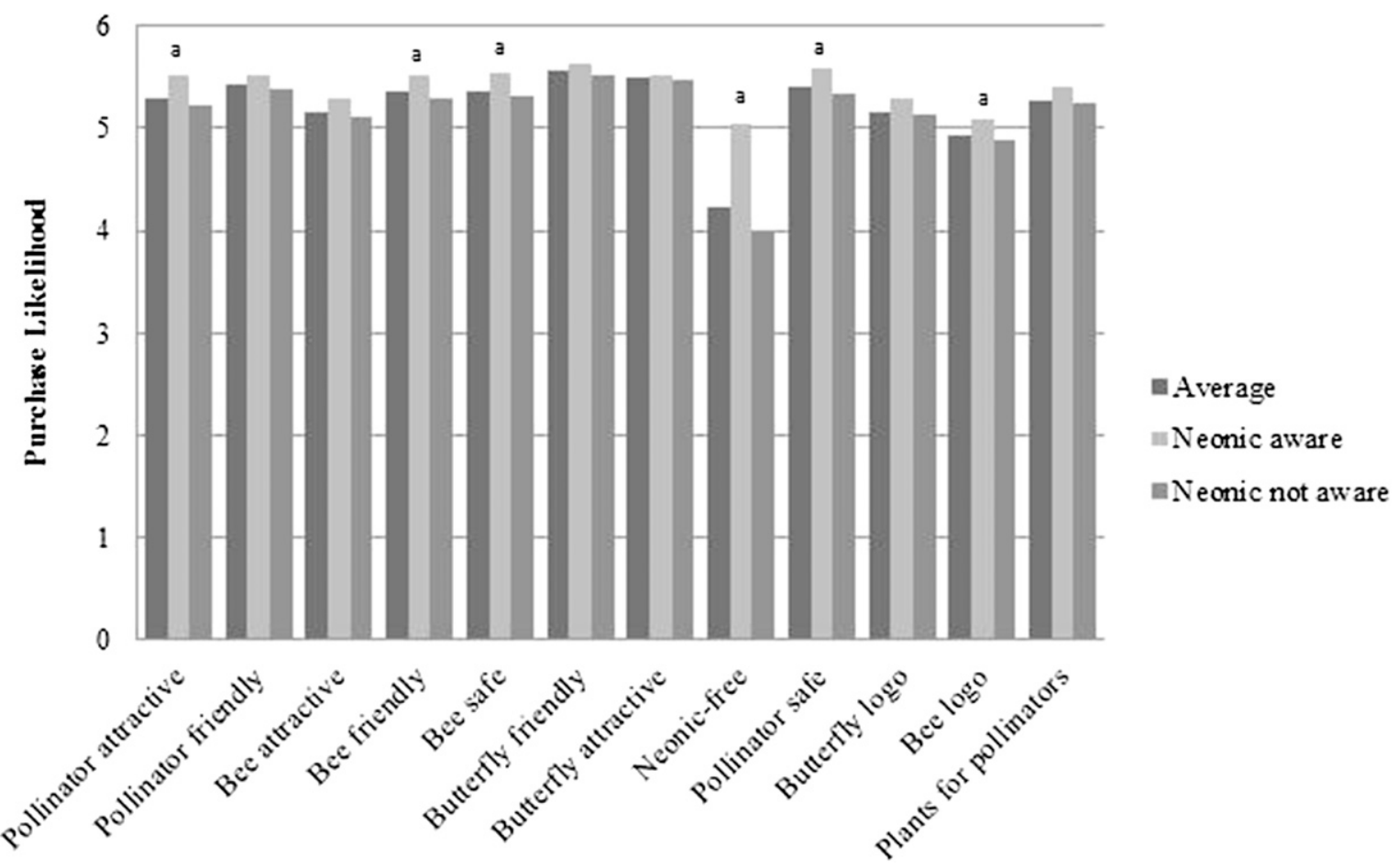

Fig. 3. Pollinator-related plant promotions' effect on consumers' purchase likelihood $(1=$ strong negative effect; $7=$ strong positive effect $)$. ${ }^{\text {aPairwise }} t$ test results indicate significance between neonic aware and not aware groups at $P<0.05$.

the last 12 months. Our summary statistics are consistent with the National Gardening Association (2009), which shows gardeners are primarily female, $\geq 45$ years old, college educated, married, in a two person household, and have a household income of over $\$ 50,000$.

Neonic insecticide awareness and knowledge. Twenty-four percent of participants (i.e., 222 out of 921) indicated they had heard of insecticides containing neonicotinoids or neonics indicating that consumer awareness of neonic insecticides is low (Table 1). Overall, participants in the neonics aware group were younger, consisted of a lower percentage of females, were more educated, and had larger households than the not aware group. Our results indicate a lower awareness of neonic insecticides than the sample collected by
Wollaeger et al. (2015). This discrepancy could be explained by Wollaeger et al.'s (2015) relatively high sampling in Oregon and Minnesota, states where a lot of media attention has been focused on systemic (i.e., neonic) insecticides.

To investigate how participants' knowledge influences their awareness of neonic insecticides, participants were asked about their knowledge levels of various topics. 
Table 3. Ordered logit regression model estimates demonstrating how consumers' neonic awareness and demographics affect their purchase likelihood for products labeled as "neonic-free."

\begin{tabular}{|c|c|c|}
\hline Variables & Coefficient ( SE) & \\
\hline Neonics aware & $1.46(0.16)$ & $* * *$ \\
\hline Age & $-0.00(0.00)$ & \\
\hline Gender & $0.09(0.13)$ & \\
\hline Income & $-0.02(0.02)$ & \\
\hline Education & $-0.25(0.14)$ & \\
\hline Household & $0.11(0.05)$ & $*$ \\
\hline Relationship & $-0.37(0.15)$ & $*$ \\
\hline \multicolumn{3}{|c|}{ Threshold parameters } \\
\hline 1 & $-2.74(0.26)$ & \\
\hline 2 & $-2.13(0.24)$ & \\
\hline 3 & $-1.47(0.24)$ & \\
\hline 4 & $0.90(0.23)$ & \\
\hline 5 & $1.66(0.24)$ & \\
\hline 6 & $2.53(0.25)$ & \\
\hline Log likelihood & $-1,394.78$ & \\
\hline $\operatorname{LR} \chi^{2}(7)$ & 123.72 & \\
\hline Prob $>\chi^{2}$ & 0.000 & \\
\hline Pseudo $R^{2}$ & 0.04 & \\
\hline
\end{tabular}

On average, participants exhibited the most knowledge about plants, gardening, and landscaping (Fig. 1). They were less knowledgeable about farming and agriculture, environmental stewardship, pollinator insects (in general), plants that improve pollinator health, landscape features that improve pollinator health, pollinator health, entomology, and bee keeping. Neonic aware consumers were more knowledgeable about all of the listed topics compared with not aware consumers. Conversely, the only topic the not aware group was knowledgeable about was plants, gardening, and landscaping, as indicated by a value greater than 4 . Although these results imply increased knowledge among neonics aware consumers, further analysis is needed to understand the relationship between knowledge and awareness of neonics. A binary logit regression was used to assess this relationship. (Marginal effects were also estimated. The marginal effect estimates are comparable to the binary logit model estimates in terms of directionality and significance. Marginal effect estimates are available up request from the corresponding author.) The results showed that consumers who are more knowledgeable about plants that improve pollinator health and entomology are more likely to be aware of neonic insecticides, partially supporting hypothesis 1 (Table 2). Consumers' knowledge of plants/gardening/landscaping, environmental stewardship, pollinator insects, pollinator health, bee keeping, pollinator-friendly landscape features, and farming/agriculture did not significantly improve consumers' awareness of neonics. Younger consumers were more likely to be aware of neonic insecticides than older consumers. In addition, consumers who had achieved a higher level of education were more likely to be aware of neonic insecticides. Gender, income, household size, and relationship status did not influence awareness.

In-store promotions and purchase likelihood. Concerning consumer preferences for in-store plant labels, most participants (44\%) preferred "pollinator friendly," followed by "plants for pollinators" (34\%), "bee friendly" (34\%), "pollinator safe" (33\%), "pollinator attractive" (26\%), "bee safe" (26\%), "butterfly friendly" (26\%), and "bee attractive" (20\%; Fig. 2). Fewer participants selected "butterfly attractive" (19\%) or a logo/image of butterflies or bees $(16 \%$ and $15 \%$, respectively). Only $6 \%$ of the sample selected "neonic-free." When comparing the neonic aware and not aware groups, both exhibited a similar pattern with "pollinator friendly" being the most preferred phrasing (Fig. 2). As expected, the neonic aware group exhibited a stronger preference for "neonic-free" $(15 \%$ of the sample) and "bee safe" labeling (32\% of the sample) when compared with the not aware group ( $2 \%$ and $24 \%$, respectively), which is consistent with previous research (Wollaeger et al., 2015). The not aware group preferred "pollinator friendly" more frequently than the aware group.

Regarding the effectiveness of pollinator promotions, most of the signs had similar positive effects on stated consumer preference with "butterfly friendly," "butterfly attractive," "pollinator friendly," and "pollinator safe" phrasing being the most effective (Fig. 3). Interestingly, the "neonic-free" phrasing had the least influence on consumers' purchase likelihood. This is likely due to lack of awareness and familiarity since only $24 \%$ of the sample was aware of neonic insecticides. When the neonic aware and not aware groups are studied separately, the results support this conclusion with aware participants' mean value equaling 5.04 and not aware participants' mean value being $3.97(P<0.001)$. Interestingly, neonic aware consumers' purchase likelihood was enhanced for the "pollinator safe," "bee safe," "bee friendly," "pollinator attractive," bee logo/image, and "neonic-free" promotions when compared with the not aware consumers. This may indicate that as a group they are more conscious of pollinator health and actively seek out products to aid pollinators.

Further analysis of the promotional results was needed to test hypothesis 2 (i.e., neonic aware consumers are more likely to purchase plants with "neonic-free" labels). Ordered logit regression model estimates show that consumers who are aware of neonic insecticides are more likely to purchase plants labeled as "neonic-free" than those who are not aware of neonics (Table 3). Participants from larger households were also more likely to purchase "neonic-free" plants than those from smaller households, potentially due to concerns about the long-term impact of pesticides on their children's and the environment (Yue et al., 2011). Age, gender, income, and education level were not significant.

\section{Conclusion}

An online survey was used to assess U.S. consumers' awareness of neonic insecticides and how that awareness influenced their purchasing behavior. Overall $24 \%$ of consumers were aware of neonic insecticides, this demographic was younger, more males, and more educated. In addition, aware consumers were more knowledgeable about plants that improve pollinator health and entomology. Not surprisingly, neonics aware consumers were more receptive of "neonic-free" labeling and their purchasing decisions were more influenced by "neonic-free" labels compared with the not aware group. However, for both groups, "neonic-free" promotions were not the most influential factor, which suggests other pollinator-related promotions may have a more positive impact on consumer purchasing behavior.

Awareness of neonic insecticides influenced consumers' perceptions, preferences, and purchase behavior for plants. Consequently, as neonic-related promotions become more prevalent consumer awareness will likely increase. Our results indicate that increased awareness could reduce demand for plants, if there is limited availability of neonic-free products. In the United States, neonic labels are still being investigated and are currently not required on plants by federal/ state agencies (US-EPA, 2013). Therefore, green industry stakeholders should investigate alternative pest management strategies should "neonic-free" labeling become mandatory.

Although the results provide interesting implications, there are several limitations that need to be acknowledged, which provide suggestions for follow-up research. First, the research methodology relied up self-reported measures. Although this method is commonly used to collect consumer preference data (McDaniel and Gates, 2010), it can lead to bias. Future studies could address this limitation using in-store sales data with items displaying various pollinator-related labels. Another limitation is that the responses were collected using an online survey, meaning individuals without access to the Internet were not be included in the sample. Despite this issue, the authors believe the benefits of online data collection (i.e., ability to collect national data, quick response rate, diversity of participants, and less data entry errors) outweigh this drawback (McDaniel and Gates, 2010). Additional research opportunities include assessing consumers' willingness to pay for neonic-free plants and evaluation of other pollinator-related promotional phrases. In addition, a cost-benefit analysis of alternative pest control options and industry barriers to adoption of the alternatives is needed to determine the economic viability of neonic-free plants.

\section{Literature Cited}

Anella, L.B., M.A. Schnelle, and D.M. Maronek. 2001. Oklahoma Proven: A plant evaluation and marketing program. HortTechnology 11:381-384.

Blacquiére, T., G. Smagghe, C.A.M. van Gestel, and V. Mommaerts. 2012. Neonicotinoids in bees: A review on concentrations, side-effects and risk assessment. Ecotoxicology 4:973-992. 
Bonroy, O. and C. Constantoatos. 2014. On the economics of labels: How their introduction affects the functioning of markets and the welfare of all participants. Amer. J. Agr. Econ. 97(1):239-259.

Breeze, T.D., A.P. Bailey, S.G. Potts, and K.G. Balcombe. 2015. A stated preference valuation of the non-market benefits of pollination services in the UK. Ecol. Econ. 111:76-85.

Chi, H.K., H.R. Yeh, and T. Yang. 2009. The impact of brand awareness on consumer purchase intention: The mediating effect of perceived quality and brand loyalty. J. Intl. Mgt. Studies 4(1):135-144.

Diffendorfer, J.E., J.B. Loomis, L. Ries, K. Oberhauser, L. Lopez-Hoffman, D. Semmens, B. Semmens, B. Butterfield, K. Bagstad, J. Goldstein, R. Widerholt, B. Mattsson, and W.E. Thogmartin. 2014. National valuation of monarch butterflies indicates an untapped potential for incentive-based conservation. Conserv. Lett. 7(3):253-262.

Fairbrother, A., J. Purdy, T. Anderson, and R. Fell. 2014. Risks of neonicotinoid insecticides to honeybees. Environ. Toxicol. Chem. 33(4):719-731.

Frankie, G.W., R.W. Thorp, M. Schindler, J. Hernandez, B. Ertter, and M. Rizzardi. 2005. Ecological patterns of bees and their host ornamental flowers in two northern California cities. J. Kans. Entomol. Soc. 78(3):227-246.

Gallai, N., J.M. Salles, J. Settele, and B.E. Vaissiere. 2009. Economic valuation of the vulnerability of world agriculture confronted with pollinator decline. Ecol. Econ. 68:810-821.

Goulson, D. 2013. An overview of the environmental risks posed by neonicotinoid insecticides. J. Appl. Ecol. 50:977-987.
Hanley, N., T.D. Breeze, C. Ellis, and D. Goulson. 2015. Measuring the economic value of pollination services: Principles, evidence and knowledge gaps. Ecosystem Serv. 142(3.4):137-143.

Krystallis, A. and P. Chrysochou. 2011. Do health claims and prior awareness influence consumers' preferences for unhealthy foods? The case of functional children's snacks. Agribusiness Intl. J. 28(1):86-102.

McDaniel, C.J. and R. Gates. 2010. Marketing research with SPSS. 8th ed. Wiley, Hoboken, NJ.

McIntyre, N.E. and M.E. Hostetler. 2001. Effects of urban land use on pollinator (Hymenoptera: Apoidea) communities in a desert metropolis. Basic Appl. Ecol. 2(3):209-218.

Mwebaze, P., G.C. Marris, G.E. Budge, M. Brown, S.G. Potts, T.D. Breeze, and A. Macleod. 2010. Quantifying the value of ecosystem services: A case study of honeybee population in the UK. 12th Annual BIOECON Conf., Venice, Italy, 27 and 28 Sept. 2010.

National Gardening Association. 2009. The impact of home and community gardening in America. South Burlington: National Gardening Association.

Pilling, E., P. Campbell, M. Coulson, N. Ruddle, and I. Tornier. 2013. A four-year field program investigating long-term effects of repeated exposure of honey bee colonies to flowering crops treated with thiamethoxam. PLoS One 8(10): e77193.

Pimentel, D. 2005. Environmental and economic costs of the application of pesticides primarily in the United States. Environ. Dev. Sustain. 7:229-252.

Sadof, C.S. and M.J. Raupp. 1987. Consumer attitudes toward the defoliation of American
Arborvitae, Thuja occidentalis, by Bagworm, Thyridopteryx ephemeraeformis. J. Environ. Hort. 5(4):164-166.

Sánchez-Bayo, F., H.A. Tennekes, and K. Goka. 2013. Impact of systemic insecticides on organisms and ecosystems, p. 367-416. In: S. Trdan (ed.). Insecticides-Development of safer and more effective technologies. InTech., Rijeka, Croatia.

US-EPA. 2013. Colony collapse disorder: European bans on neonicotinoid pesticides. United States Environmental Protection Agency, Washington DC. 9 Jan. 2015. <http://www. epa.gov/pesticides/about/intheworks/ccdeuropean-ban.html>.

van der Sluijs, J.P., N. Simon-Delso, D. Goulson, L. Maxim, J.M. Bonmatin, and L.P. Belzunces. 2013. Neonicotinoids, bee disorders and the sustainability of pollinator services. Curr. Opin. Environ. Sustain. 5:293-305.

Wollaeger, H.M., K.L. Getter, and B.K. Behe. 2015. Consumer preferences for traditional, neonicotinoid-free, bee-friendly, or biological control pest management practices on floriculture crops. HortScience 50:721-732.

Wratten, S.D., M. Gillespie, A. Decortye, E. Mader, and N. Desneux. 2012. Pollinator habitat enhancement: Benefits to other ecosystem services. Agr. Ecosystems and Environ. 159:112-122.

Yue, C., J.H. Dennis, B.K. Behe, C.R. Hall, B. Campbell, and R.G. Lopez. 2011. Investigating consumer preference for organic, local, or sustainable plants. HortScience 46(4):610-615.

Zalom, F.G., N. Toscano, and F.J. Byrne. 2005. Managing resistance is critical to future use of pyrethroids and neonicotinoids. Calif. Agr. 59:11-15. 